SOME REACTIONS OF N-(4-ACETYLPHENYL)-2-CYANOACET . . 217

SOME REACTIONS OF $N$-(4-ACETYLPHENYL)-2-CYANOACETAMIDE

WITH VARIOUS ELECTROPHILIC REAGENTS: SYNTHESIS OF

THIAZOLIDINONES,3,5-DICYANO-6-AMINO-2-OXOPYRIDINE, 2-IMINO-

2H-CHROMENE-3-CARBOXAMIDE AND 5-IMINO-3H-CHROMENO[3,4-

C]PYRIDINE-1-CARBONITRILE DERIVATIVES

\title{
MOHAMMED ABD-ELRASHID SALEM
}

Chemistry Department, Faculty of Science, Alazhar University, 11284 Nasr City, Cairo, Egypt.

\begin{abstract}
Reactions of N-(4-acetylphenyl)-2-cyanoacetamide (1) with several electrophilic reagents are reported. Thus, N-(4-acetylphenyl)-2-cyano-2-(3-phenylthiazol-2-ylidene)acetamide derivatives 4,5a-c were obtained. 4,6-dimethyl-2-oxo-1-(4-acetylphenyl)-1,2dihydropyridine-3-carbonitrile (8) and their thiosemicarbazone derivative (9) were synthesized. Treatment of $\mathbf{1}$ and its thiosemicarbazone derivative $\mathbf{6}$ with $\alpha$ cyanocinnamonitrile 10a,b under Michael reaction conditions afforded N-(4-acetylphenyl)-2cyano-3-(4-methoxyphenyl)acrylamide (12) and 6-amino-4-(4-chlorophenyl)-3,5-dicyano-2oxo-pyridine derivative 15, respectively. Condensation of $\mathbf{6}$ with $\alpha$-halocarbonyl compounds gave 1,3-thiazole derivatives $\mathbf{1 6 a}, \mathbf{b} \& \mathbf{1 7 a}, \mathbf{b}$ which on treatment of $\mathbf{1 6 a}, \mathbf{1 7 a}$ with salicyaldehyde gave 2-iminochromene derivatives 18 and 19 , respectively. Treatment of 1 with phenolic aldehydes yielded 2-iminochromenes 21a,b which on treatment with ethanolic $\mathrm{HCl}$ gave chromene-2-one derivatives 22a,b, respectively. Treatment of 21a with malononitrile and/or ethyl cyanoacetate gave chromeno[3,4-c]pyridine derivatives $\mathbf{2 4} \& \mathbf{2 6}$. IR, ${ }^{1}$ HNMR and MS for the new synthesized compounds are cited.
\end{abstract}

\section{Introduction}

A combination between $\mathrm{NH}-\mathrm{C}=\mathrm{O} \& \mathrm{CH}_{2} \mathrm{CN}$ in addition to acetyl group in cyanoacetamide derivative $\mathbf{1}$ open wide synthetic opportunities for further reactions and utilizing as a ready starting materials in the synthesis of many heterocyclic compounds $^{1-8}$. As an extension of our efforts for the construction of biologically active heterocyclic derivatives ${ }^{9-13}, N$-(4-acetylphenyl)-2-cyanoacetamide (1) is used in this article for the synthesis of interested biologically active thiazole derivatives ${ }^{14-}$ ${ }^{19}$. Polyfunctionallized pyridine compounds ${ }^{20-26}$, conjugated thiazole chromene moieties ${ }^{27-35}$ and combined pyridine chromene nucleus ${ }^{36-38}$ were obtained through the different chemical transformation reaction with varieties of electrophilic reagents under different reactions conditions.

\section{Results and discussion}

Reaction of cyanoacetamide derivative $\mathbf{1}$ with phenyl isothiocyanate in DMF in presence of potassium hydroxide, at room temperature gave non-isolable intermediate potassium sulphide salt 2, Equation 1. 
8<smiles>CC(=O)c1ccc(NC(=O)CC#N)cc1</smiles>

(1)

(2)

\section{Equation 1}

Cyclocondensation of the intermediate 2 with chloroacetone (3a) at room temperature afforded the corresponding 4-methylthiazole derivative $\mathbf{4}$, Scheme 1. Infrared spectrum of 4 showed a nitrile absorption band at $2176 \mathrm{~cm}^{-1}$. The ${ }^{1} \mathrm{HNMR}$ spectrum displayed a characteristic two singlet signals at 1.86, $2.49 \mathrm{ppm}$ due to two methyl groups in addition to singlet at $\delta=6.98 \mathrm{ppm}$ for thiazole $\mathrm{H} 5$. Also, treatment of intermediate 2 with respective $\alpha$-halo ester $\mathbf{3 b}$-d at room temperature gave 4thiazolidinone derivatives $\mathbf{5 a - c}$. The infrared spectrum of $\mathbf{5 a}$ showed nitrile absorption bands at $2194 \mathrm{~cm}^{-1}$, while its the mass spectrum was compatible with a molecular formula $\mathrm{C}_{20} \mathrm{H}_{15} \mathrm{~N}_{3} \mathrm{O}_{3} \mathrm{~S}\left(\mathrm{M}^{+}=377\right),{ }^{1} \mathrm{HNMR}$ spectrum of $5 \mathbf{a}$ revealed a singlet at $\delta 4.02 \mathrm{ppm}$ corresponding to an the methylene group of thiazolidinone. The reaction may be assumed to proceed via initial alkylation followed by intramolecular cyclization with elimination of ethanol molecule.

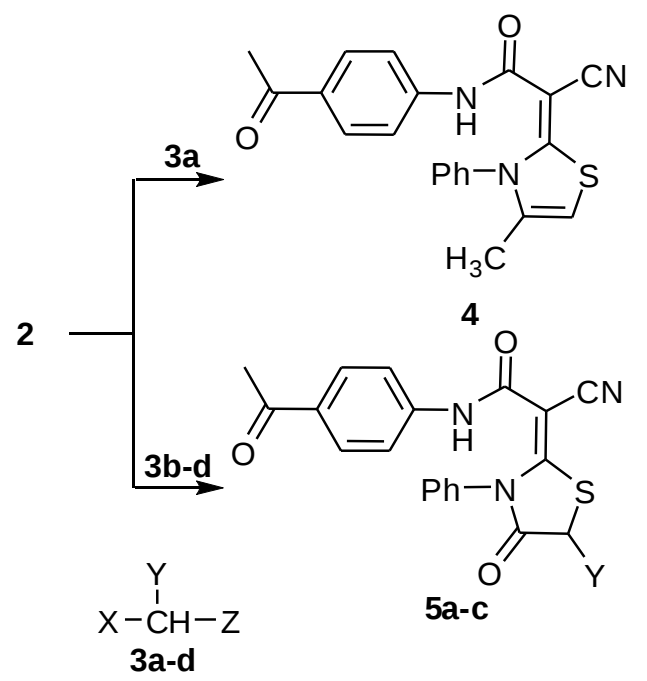

3a; $X=\mathrm{Cl}, Y=\mathrm{COCH}_{3}, \mathrm{Z}=\mathrm{H}$

3b; $X=\mathrm{Cl}, Y=\mathrm{CO}_{2} \mathrm{Et}, \mathrm{Z}=\mathrm{H}$

3c; $X=\mathrm{Br}, \mathrm{Y}=\mathrm{CH}_{3}, \mathrm{Z}=\mathrm{CO}_{2} \mathrm{Et}$

3d; $X=\mathrm{Br}, \mathrm{Y}=\mathrm{C}_{2} \mathrm{H}_{5}, \mathrm{Z}=\mathrm{CO}_{2} \mathrm{Et}$

5a; $\mathrm{Y}=\mathrm{H}$,

$5 \mathbf{b} ; \mathrm{Y}=\mathrm{CH}_{3}$

5c; $\mathrm{Y}=\mathrm{C}_{2} \mathrm{H}_{5}$

Scheme 1 
Also, cyclocondensation of cyanoacetamide derivative 1 with acetylacetone furnished 4,6-dimethyl-2-oxo-1-(4-acetylphenyl)-1,2-dihydropyridine-3-carbonitrile (8) via intramolecular heterocyclization of the non isolable intermediate 7 by loss of a water molecule, Scheme 2. The ${ }^{1}$ HNMR spectrum of 8 revealed signals at $\delta=1.97$, 2.37 and $2.49 \mathrm{ppm}$ for two $\mathrm{CH}_{3}$ and $\mathrm{COCH}_{3}$ with a singlet at $\delta=6.46 \mathrm{ppm}$ for $\mathrm{CH}$ pyridine. Simillarby, the reaction of compound 6 with ethyl chloroacetate (3b) and ethyl $\alpha$-browopropionate (3c) resulted in the formation of 4-thiazolidinone derivatives $17 \mathrm{a}$, b on the basis of the spectral data. Condensation of 4,6dimethylpyridine derivative $\mathbf{8}$ with thiothemicarbazide produced pyridine-N-(4acetylphenyl thiosemicarbazone) derivative 9. This product was readily demonstrated on the basis of spectral data. Its infrared spectrum afforded bands at 3460, 3348, $3228\left(\mathrm{NH}_{2} / \mathrm{NH}\right), 2222 \mathrm{~cm}^{-1}(\mathrm{C} \equiv \mathrm{N})$. Mass spectrum of compound 9 exhibited a molecular ion peak at $\mathrm{m} / \mathrm{z}=339$ (5.5\%). The thiosemicarbazone derivative $\mathbf{9}$ could also be obtained in a good yield via the reaction of compound $\mathbf{6}$ with acetylacetone, Scheme 2.

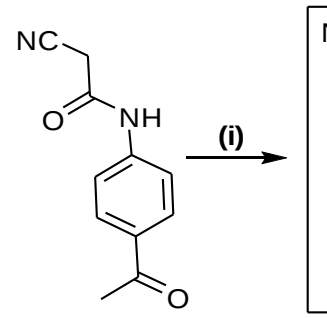<smiles>CC(C)=NC=S(N)N=C(C)c1ccc(NC(=O)CC#N)cc1</smiles>

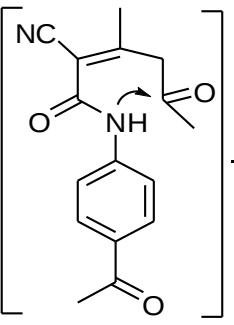

7

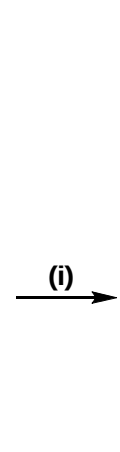<smiles>CC(=O)c1ccc(-n2c(C)cc(C)c(C#N)c2=O)cc1</smiles>

8

(ii)<smiles>Cc1cc(C)n(-c2ccc(C(=O)N=C=N)cc2)c(=O)c1C#N</smiles>

Method and reagents:(i)Acetylacetone/fusion, (ii)Thiosemicarbazide/dioxan

Scheme 2

The reaction of cyanoacetamide derivative 1 with $\alpha$-cyano-4methoxycinnamonitrile (10a) in refluxing ethanol resulted in the formation of $\mathrm{N}$-(4- 
0

acetylphenyl)-2-cyano-3-(4-methoxyphenyl)acrylamide (12), Scheme 3. The ${ }^{1} \mathrm{HNMR}$ spectrum of $\mathbf{1 2}$ displayed a characteristic singlet signal at $\delta=3.87 \mathrm{ppm}$ due to methoxy group, in addition to a singlet at $\delta=8.24$ for $\mathrm{CH}$-benzylidine together with a singlet at $\delta=10.56 \mathrm{ppm}$ for $\mathrm{NH}$ group. It seems that $\mathbf{1 2}$ was formed via Michael type addition of the methylene function in $\mathbf{1}$ to the activated double bond of 10a to yield acyclic Michael adduct $\mathbf{1 1}$ which then spontaneously loses the malononitrile molecule. Further confirmation, compound $\mathbf{1 2}$ could also be obtained in good yield via the reaction of $\mathbf{1}$ with anisaldehyde. Similarly thiosemicarbazone derivative 6 reacted with $\alpha$-cyano-4-methoxycinnamonitrile (10a) to give the acrylamide derivative $\mathbf{1 4}$ not the other possible pyridine derivative 15 . ${ }^{1} \mathrm{HNMR}$ spectrum of $\mathbf{1 4}$ revealed the presence of signals at $\delta=3.87,8.22 \mathrm{ppm}$ for methoxy and $\mathrm{CH}$-benzylidene protons, respectively. The proposed structure of $\mathbf{1 4}$ was also confirmed through its synthesis from condensation of thiosemicarbazone $\mathbf{6}$ with anisaldehyde. On the other hand, Michael addition of the methylene function of $\mathbf{6}$ to the activated double bond of $\alpha$-cyano-4-chlorocinnnamonaitrile (10b) yielded acyclic Michael adduct $\mathbf{1 3}$ which on cyclization followed by aromatization gave pyridine type 15. ${ }^{1} \mathrm{HNMR}$ of 15 revealed a signal at $\delta=2.36 \mathrm{ppm}\left(\mathrm{CH}_{3}\right)$ and a $\mathrm{D}_{2} \mathrm{O}$ exchangeable signals at 8.40,10.17, 10.29 and $10.45 \mathrm{ppm}$ due to $\mathrm{NH}_{2}, 2 \mathrm{NH}$ and $\mathrm{SH}$ functions. Mass spectrum of $\mathbf{1 5}$ exhibited peak at $\mathrm{m} / \mathrm{z} 387$ corresponding to (M$\mathrm{NH}_{2} \mathrm{CSNH}_{2}$ : 3.0\%), Scheme 3.
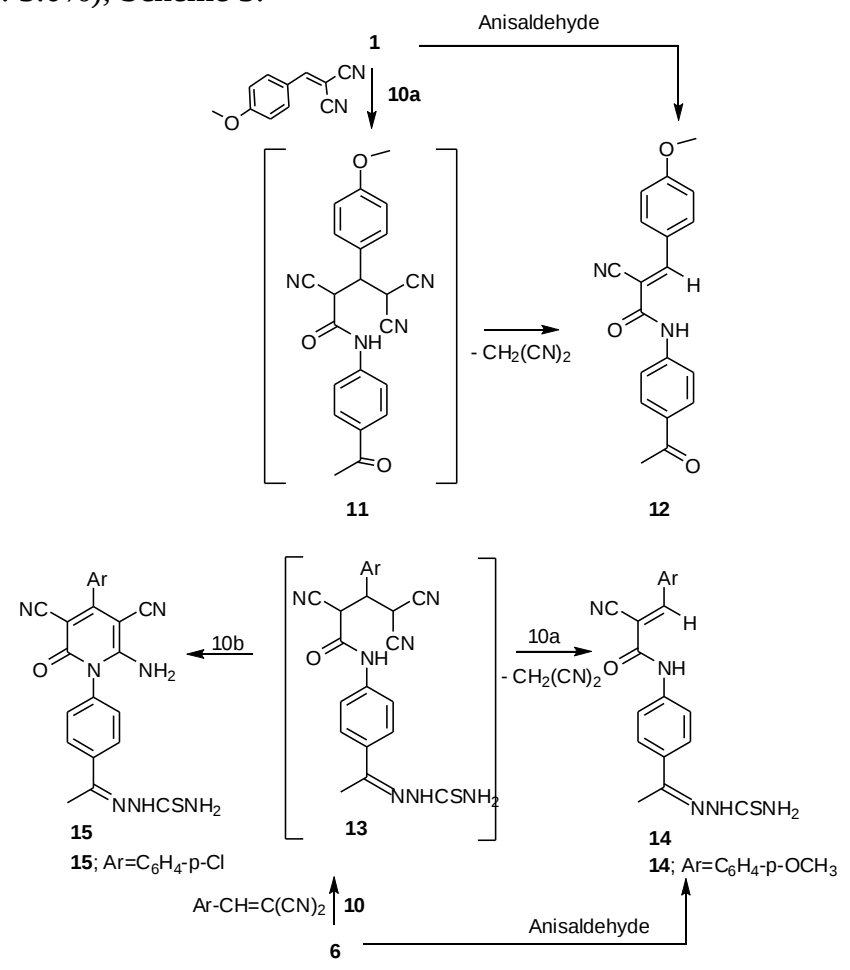

Scheme 3 
SOME REACTIONS OF N-(4-ACETYLPHENYL)-2-CYANOACET ... 221

The reactivity of compound $\mathbf{6}$ toward some $\alpha$-halocarbonyl compounds to afford some thiazole derivatives was investigated. Thus, condensation of $\mathbf{6}$ with chloroacetone (3a) and p-nitrophenacyl bromide (3e) in refluxing ethanol and in the presence of catalytic amount of fused sodium acetate resulted in the formation 1,3thiazole derivative 16a,b. The structure of the isolated compounds $\mathbf{1 6 a}, \mathbf{b}$ was confirmed on the basis of elemental analysis and spectral data. The ${ }^{1} \mathrm{HNMR}$ spectra of the isolated products, revealed in each case singlet at $7.71 \mathrm{ppm}$ assigned for $\mathrm{CH}$ thiazole. Cyclocondensation of thiazole derivatives 16a and 17a with salicylaldehyde in refluxing ethanol containing a catalytic amount of ammonium acetate resulted in the formation of 2-iminochromene derivatives 18 and 19. The structures of 18 and 19 were established on the basis of their elemental analysis and spectral data. The ${ }^{1} \mathrm{HNMR}$ spectra of the isolated products revealed in each case a singlet for CH-chromene in the region 8.57-8.60 ppm, together with $\mathrm{D}_{2} \mathrm{O}$ exchangeable signal in the region 9.25-12.89 ppm due to three $\mathrm{NH}$ functions (cf. Experimental part). Alternatively, products 18 and 19 could be obtained via an independent stepwise synthetic route involving the cyclocondensation of $\mathbf{6}$ with an equimolar amount of salicylaldehyde in the presence of a catalytic amount of ammium acetate to afford the corresponding chromene derivative 20. The latter, in turn, reacted with chloroacetone (3a) and ethylchloroacetate (3b) to afford a single product in each case found to be identical with 18 and 19, Scheme 4.

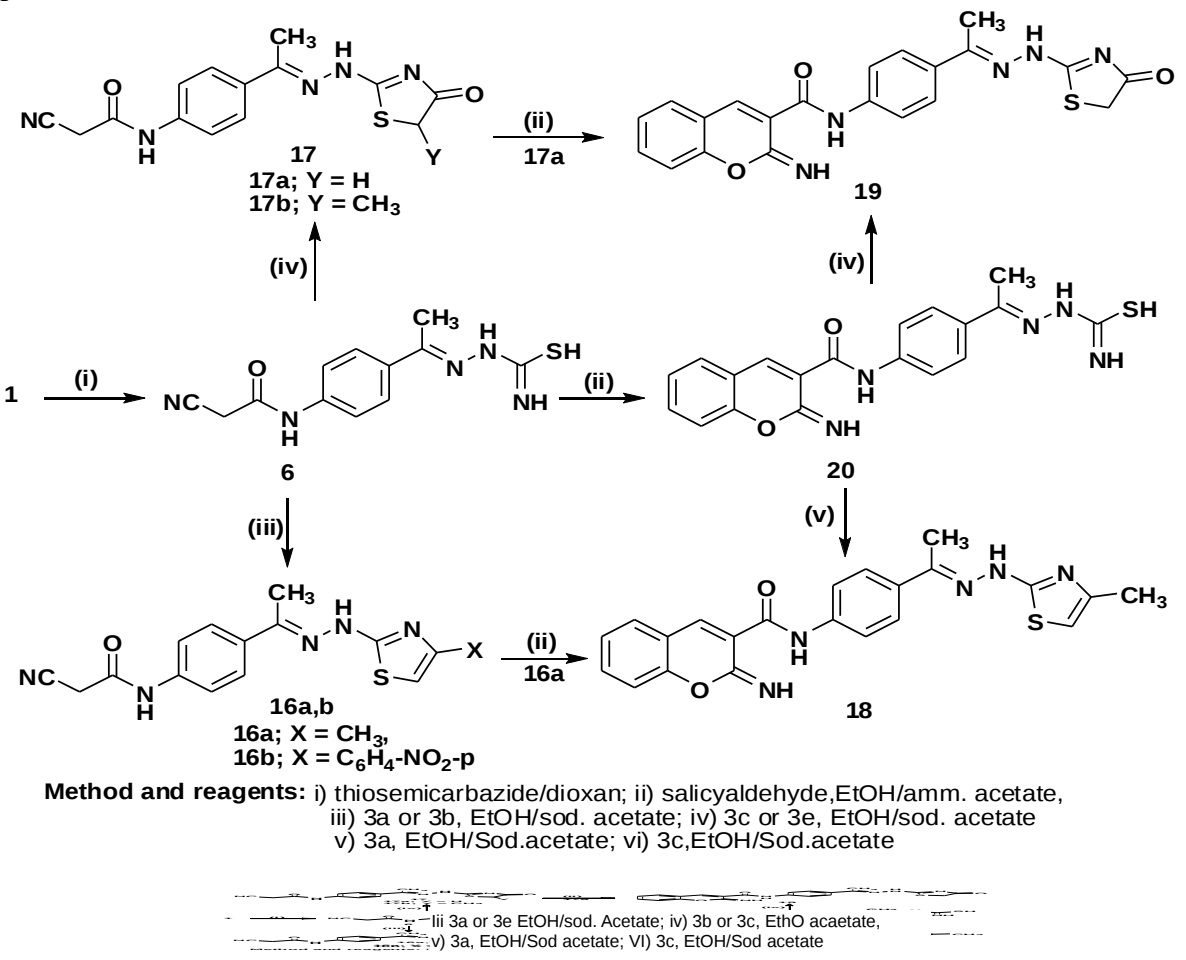

Scheme $\mathbf{4}$ 
Cyclocondensation of $N$-(4-acetylphenyl)-2-cyanoacetamide (1) with salicylaldehyde or 2-hydroxy-1-naphthaldehyde in refluxing ethanolic ammonium acetate furnished 2-iminochromene and 2-iminobenzo[f]chromene derivative 21a, b (Scheme 5), ${ }^{1} \mathrm{HNMR}$ spectrum of 21a revealed a singlet at $\delta 8.58 \mathrm{ppm}$ assigned for $\mathrm{CH}$-chromene with two singlets for $2 \mathrm{NH}$ groups at $\delta 9.27,13.12 \mathrm{ppm}$ (disappeared after addition of $\mathrm{D}_{2} \mathrm{O}$ ). The mass spectrum of $\mathbf{2 1 \mathbf { b }}$ exhibited a molecular ion peak at $\mathrm{m} / \mathrm{z} 356$ (20.5\%) together with the base peak at $\mathrm{m} / \mathrm{z} 120$. On the other hand, cyclocondensation of $\mathbf{1}$ with salicylaldehyde or 2-hydroxy-1-naphthaldehyde in refluxing acetic anhydride containing catalytic amounts of sodium acetate, yielded chromene-2-one derivatives 22a, b. Infrared spectrum of 22a afforded absorption bands at 3100 and $1702 \mathrm{~cm}^{-1}$ corresponding to amide $\mathrm{NH}$ and carbonyl groups, respectively. The ${ }^{1} \mathrm{HNMR}$ (DMSO- $\mathrm{d}_{6}$ ) of 22a showed a singlet at $\delta 8.92 \mathrm{ppm}(\mathrm{CH}-$ chromene) and $10.87 \mathrm{ppm}(\mathrm{NH})$. The structure of the latter compound 22 further confirmed by another route of preparation via the hydrolysis of 2-iminochromene derivative 21 with ethanolic $\mathrm{HCl}$ under reflux condition, Scheme 5. (cf. Experimental part).

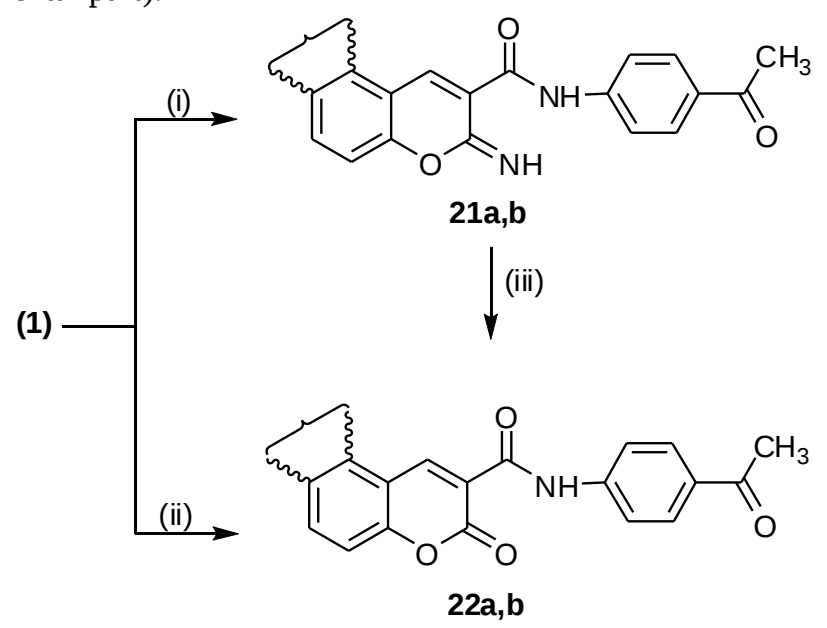

Method and reagents: (i) salicylaldehyde and/or 2-hydroxynaphthaldehyde, $\mathrm{EtOH} / \mathrm{amm}$.acetate, (ii) salicylaldehyde and/or 2-hydroxynaphthaldehyde, acetic anhydride/sod. acetate, (iii) EtOH/HCl

\section{Scheme 5}

The resulting chromene derivative 21a have latent functional substituents which have the potential for further chemical transformation giving new routes for preparation of condensed chromeno[3,4-c]pyridine derivatives. Thus, treatment of 
SOME REACTIONS OF N-(4-ACETYLPHENYL)-2-CYANOACET ... 223 compound 21a with malononitrile under reflux in dioxane in the presence of piperidine afforded the novel chromeno[3,4-c]pyridine derivative $\mathbf{2 4}$. The molecular structure of $\mathbf{2 4}$ was established through analytical and spectral data. Its infrared spectrum showed absorption bands at 3438, 3316 and 2208 and $1650 \mathrm{~cm}^{-1}$ due to amino, cyano and carbonyl function groups, respectively. Also, ${ }^{1} \mathrm{HNMR}$ spectrum showed the appearance of a $\mathrm{D}_{2} \mathrm{O}$ exchangeable signals at $\delta=7.79$ and $8.40 \mathrm{ppm}$ due to the amino and imino functions. Compound 24 may be assumed to proceed via the formation of Michael type adduct $\mathbf{2 3}$ which cyclize and aromatize under reaction condition. Finally, chromeno[3,4-c]pyridine derivative $\mathbf{2 6}$ was achieved by reaction of 2-iminochromene derivative 21a with ethyl cyanoacetate and the other possible structure 27 was excluded on the basis of elemental analysis and spectral data. Its IR spectrum revealed the presence of hydroxyl, nitrile and the carbonyl functional, and its ${ }^{1} \mathrm{HNMR}$ spectrum showed signals at $\delta=8.68$ and $11.66 \mathrm{ppm}$ assigned to $\mathrm{OH}$ and $\mathrm{NH}$ groups (cancelled with $\mathrm{D}_{2} \mathrm{O}$ ). It can be postulated that the reaction initially proceeds via the formation of Michael type adduct $\mathbf{2 5}$ that subsequently cyclize through elimination of ethanol, Scheme 6.

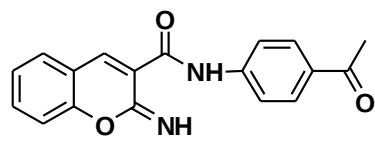

212

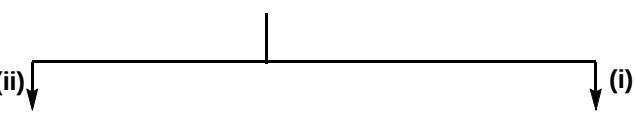

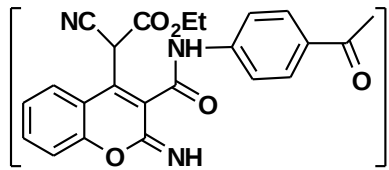

25

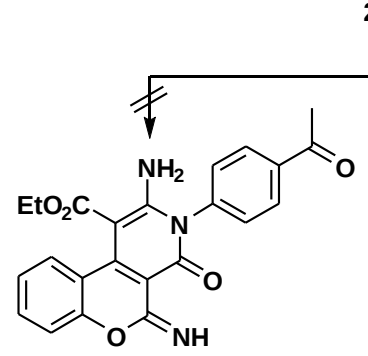

27<smiles>N#CC(C#N)c1c(C(=O)Nc2ccc(C(=O)CC3CC3)cc2)c(=N)oc2ccccc12</smiles>

23<smiles>CC(=O)c1ccc(-n2c(N)c(C#N)c3c(c(=N)oc4ccccc43)c2=O)cc1</smiles>

Method and reagents: (i)malononitrile,dioxane/pipredine, (ii)ethylcyanoacetate,dioxane/pipredine 


\section{Experimental}

All melting points are uncorrected. IR spectra $(\mathrm{KBr})$ were measured on Shimadzu 440 spectrometer, ${ }^{1} \mathrm{H}$ NMR spectra were obtained in DMSO on a Varian Gemini $200 \mathrm{MHz}$ spectrometer using TMS as internal standard; chemical shifts are reported as (ppm). Mass spectra were obtained on GCMS \QP 1000 Ex mass spectrometer at $70 \mathrm{ev}$. Elemental analyses were carried out at the Microanalytical Center, Faculty of Science (Cairo University, Egypt).

Preparation of compounds 4, 5a-c: General procedure: A mixture of compound 1 (0.01 mole), appropriate $\alpha$-halo compounds namely (chloroacetone 3a, ethylchloroacetate 3b, ethyl $\alpha$-bromopropionate 3c, ethyl $\alpha$-bromobutyrate 3d) (0.01 mole) and sodium acetate $(0.01$ mole) in ethanol $(30 \mathrm{~mL})$ was refluxed for $3 \mathrm{~h}$. The solid product which produced on heating was collected and recrystallized from the acetic acid.

\section{$\mathrm{N}$-(4-Acetylphenyl)-2-cyano-2-(4-methyl-3-phenylthiazol-2(3H)ylidene) acetamide} (4)

Yield (70\%); White solid (Acetic acid); Mp 230-232Cㅇ IR (KBr): $\bar{\nu}=3460$ $(\mathrm{NH}), 2176(\mathrm{C} \equiv \mathrm{N}), 1672(\mathrm{C}=\mathrm{O}) \mathrm{cm}^{-1} ;{ }^{1} \mathrm{HNMR}\left(200 \mathrm{MHz}, \mathrm{DMSO}-\mathrm{d}_{6}\right): \delta=1.86$ (s, $3 \mathrm{H}, \mathrm{CH}_{3}$ ), 2.49 (s, 3H, $\mathrm{COCH}_{3}$ ), 6.98 (s, 1H, thiazole-H5), 7.50-7.86 (m, 9H, Ar-H), 9.03 (s, $1 \mathrm{H}$, NH; exchange). Anal. Calc. for $\mathrm{C}_{21} \mathrm{H}_{17} \mathrm{~N}_{3} \mathrm{O}_{2} \mathrm{~S}$ : C, 67.20; H, 4.53; N, 11.20. Found: C, 67.05; H, 4.40; N, 11.07 .

\section{$\mathrm{N}$-(4-Acetylphenyl)-2-cyano-2-(4-oxo-3-phenylthiazolidin-2-ylidene)-acetamide} (5a)

Yield (75\%); White solid (Dioxane); Mp 240-243C'; IR (KBr): $\bar{\nu}=3334$ (NH), $2194(\mathrm{C} \equiv \mathrm{N}), 1748$ (C=O; thiazolidinone), 1674 (C=O; amide) $\mathrm{cm}^{-1}$; ${ }^{1} \mathrm{HNMR}$ (200 MHz, DMSO-d $\mathrm{d}_{6}$ ): $\delta=2.49$ (s, 3H, $\mathrm{COCH}_{3}$ ), 4.02 (s, 2H, $\mathrm{CH}_{2}$-thiazolidinone), 7.42-7.91 (m, 9H, Ar-H). 9.74 (s, $1 \mathrm{H}, \mathrm{NH}$; exchange). Anal. Calc. for $\mathrm{C}_{20} \mathrm{H}_{15} \mathrm{~N}_{3} \mathrm{O}_{3} \mathrm{~S}$ : C, 63.66; H, 3.97; N, 11.14. Found: C, 63.49; H, 3.67; N, 10.92.

MS (EI): m/z (\%) = 377 (M+ 15.6), 243 (29.4), 215 (72.1), 132 (28.4) and 77(100, base peak).

$\mathrm{N}$-(4-Acetylphenyl)-2-cyano-2-(5-methyl-4-oxo-3-phenylthiazolidin-2-ylidene)acetamide (5b) 
Yield (65\%); Beige solid (Dioxane); Mp 235-237C ; IR (KBr): $\bar{\nu}=3360$ (NH), 2926 (aliph.CH), $2194(\mathrm{C} \equiv \mathrm{N}), 1728$ (C=O; thiazolidinone), 1670 (C=O; amide) $\mathrm{cm}^{-}$ 1.; ${ }^{1} \mathrm{HNMR}$ (200 MHz, DMSO-d ${ }_{6}$ ): $\delta=1.61$ (d, 3H, $\mathrm{CH}_{3}$ ), 2.49 (s, 3H, $\mathrm{COCH}_{3}$ ), 4.28 (q, 1H, thiazoldinone-H5), 7.45-7.91 (m, 9H, Ar-H), 9.77 (s, 1H, NH; exchange). Anal. Calc. for $\mathrm{C}_{21} \mathrm{H}_{17} \mathrm{~N}_{3} \mathrm{O}_{3} \mathrm{~S}$ : C, 64.45; H, 4.34; N, 10.74. Found: C, 64.24; H, 4.08; $\mathrm{N}, 10.45$.

\section{N-(4-Acetylphenyl)-2-cyano-2-(5-ethyl-4-oxo-3-phenylthiazolidin-2-ylidene)acet- amide (5c)}

Yield (65\%); Beige solid (Dioxane); Mp 243-245C ${ }^{\circ}$; IR (KBr): $\bar{\nu}=3400$ (NH), 2950 (aliph.CH), $2198(\mathrm{C} \equiv \mathrm{N}), 1740\left(\mathrm{C}=\mathrm{O}\right.$; thiazolidinone), 1666 (C=O; amide) $\mathrm{cm}^{-}$ '; ${ }^{1} \mathrm{HNMR}$ (200 MHz, DMSO-d 6 ): $\delta=1.03$ (t, 3H, $\mathrm{CH}_{3}$ ), 1.96 (p, 2H, $\mathrm{CH}_{2}$ ), 2.49 (s, $3 \mathrm{H}, \mathrm{COCH}_{3}$ ), 4.30 (t, 1H, thiazoli-dinone-H5), 7.41-7.91 (m, 9H, Ar-H), 9.78(s, 1H, $\mathrm{NH}$; exchange). Anal. Calc. for $\mathrm{C}_{22} \mathrm{H}_{19} \mathrm{~N}_{3} \mathrm{O}_{3} \mathrm{~S}$ : C, 65.18; H, 4.69; N, 10.37. Found: C, 64.95; H, 4.49; N, 10.12 .

\section{2-(1-(4-(2-Cyanoacetamido)phenyl)ethylidene) hydrazinecarbimidothioic acid (6)}

A mixture of compound 1 (0.01 mole), thiosemicarbazide; 0.01 mole) in dioxane (30 mL) was refluxed for $3 \mathrm{~h}$. The resulting solid was filtered off and recrystallized from acetic acid as yellow solid; Yield (85\%); Mp 215-217 $\mathrm{C}$; IR (KBr): $\bar{\nu}=$

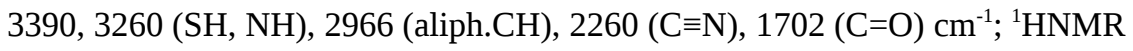
(200 MHz, DMSO-d $\mathrm{d}_{6}$ ): $\delta=2.27$ (s, 3H, $\mathrm{CH}_{3}$ ), 3.91 (s, $2 \mathrm{H}, \mathrm{CH}_{2}$ ), 7.54-7.93 (m, 5H, Ar-H and NH; exchange). 8.22, 10.14 and 10.39 (3s, 3H, 2NH \& SH; exchange). Anal. Calc. for $\mathrm{C}_{12} \mathrm{H}_{13} \mathrm{~N}_{5} \mathrm{OS}$ : C, 52.36; H, 4.72; N, 25.45. Found: C, 52.16; H, 4.49; N, 25.27.

\section{1-(4-Acetylphenyl)-4,6-dimethyl-2-oxo-1,2-dihydropyridine-3-carbonitrile (8)}

Equimolar amounts of $\mathbf{1}$ (0.01 mole) and acetyl acetone ( 0.01 mole) with a few drops of piperidine in an oil bath were refluxed for $1 \mathrm{~h}$ at $160^{\circ} \mathrm{C}$, then allowed to cool. The solid product was collected and recrystallized from acetic acid to give $\mathbf{8}$.

Yield (55\%); White solids; Mp 290-292C ${ }^{\circ}$ IR (KBr): $\bar{\nu}=3060$ (arom-CH), 2214(C $\equiv \mathrm{N}) .1660(\mathrm{C}=\mathrm{O}) \mathrm{cm}^{-1}$; ${ }^{1} \mathrm{HNMR}\left(200 \mathrm{MHz}, \mathrm{DMSO}-\mathrm{d}_{6}\right): \delta=1.97,2.37,2.49$ (3s, 9H, 3CH 3 ), 6.46 (s, 1H, pyridine-H5), 7.49, 8.13 (2d, 4H, Ar-H). Anal. Calc. for $\mathrm{C}_{16} \mathrm{H}_{14} \mathrm{~N}_{2} \mathrm{O}_{2}$ : C, 72.18; H, 5.26; N, 10.52. Found: C, 72.05; H, 5.10; N, 10.30 . 
Method A: Equimolar amounts of 6 (0.01 mole) and acetyl acetone (0.01 mole) with a few drops of piperidine in an oil bath were refluxed for $1 \mathrm{~h}$ at $160^{\circ} \mathrm{C}$, then allowed to cool. The solid product was collected and recrystallized from acetic acid to give $\mathbf{9}$.

Method B: Equimolar amounts of 8 ( 0.1 mole) and thiosemicarbazide ( 0.1 mole) were refluxed in dioxane $(30 \mathrm{~mL})$ for $3 \mathrm{~h}$ and then allowed to cool. The solid product was collected and recrystallized from acetic acid to give $\mathbf{9}$.

Yield (80\%); Yellow crystals; Mp 250-252C ; IR (KBr): $\bar{\nu}=3460,3348,3228$ $\left(\mathrm{NH} / \mathrm{NH}_{2}\right), 2222(\mathrm{C} \equiv \mathrm{N}), 1648(\mathrm{C}=\mathrm{O}) \mathrm{cm}^{-1}$; ${ }^{1} \mathrm{HNMR}$ (200 MHz, DMSO-d $\left.{ }_{6}\right): \delta=1.98$, 2.27, 2.49 (3s, 9H, 3CH $\mathrm{CH}_{3}$, 6.46 (s, $1 \mathrm{H}$, pyridine-H5), 7.31, 8.11 (2d, 4H, Ar-H), 8.02, 8.30, 10.26 (3s, 3H, 2NH \& SH; exchange). Anal. Calc. for $\mathrm{C}_{17} \mathrm{H}_{17} \mathrm{~N}_{5} \mathrm{OS}$ : C, 60.17; H, 5.01; N, 20.64. Found: C, 59.95; H, 4.85; N, 20.40.

MS (EI): m/z (\%) = 339 (M+ 5.5), 322 (30.2), 250 (44.9), 224 (19.6), 179 (9.4) and 76 (100, base peak).

\section{Preparation of compounds 12 and 14: General procedure:}

Method A: Amixture of 1 and/or 6 (0.01 mole) and $\alpha$-cyano-4methoxycinnamonitrile (10a) $(0.01 \mathrm{~mole})$ in ethanol $(30 \mathrm{~mL})$ was treated with piperidine $(0.5 \mathrm{~mL})$ and the reaction mixture was refluxed for $3 \mathrm{~h}$. The solid product which produced on heating was filtered off and recrystallized from the proper solvent to give 12 and 14 respectively.

Method B: A mixture of compound 1 and/or 6 (0.01 mole), anisaldehyd (0.01 mole) and piperidine $(0.5 \mathrm{~mL})$ in ethanol $(30 \mathrm{~mL})$ was refluxed for $1 \mathrm{~h}$. The solid product which produced on heating was collected and recrystallized to furnish 12 and 14.

\section{N-(4-acetylphenyl)-2-cyano-3-(4-methoxyphenyl)acrylamide(12)}

Yield (50\%); Green crystals (Dioxane); Mp 180-182 ${ }^{\circ} \mathrm{C}$; IR $(\mathrm{KBr}): \bar{\nu}=$ 3310(NH), 3012 (arom.CH), $2220(\mathrm{C} \equiv \mathrm{N}) .1678(\mathrm{C}=\mathrm{O}) \mathrm{cm}^{-1}$; ${ }^{1} \mathrm{HNMR}(200 \mathrm{MHz}$, DMSO-d $\left.\mathrm{d}_{6}\right): \quad \delta=2.49$ (s, 3H, $\mathrm{CH}_{3}$ ), 3.87 (s, 3H, $\mathrm{OCH}_{3}$ ), 7.16- 8.05 (m, 8H, Ar-H), 8.24 (s, $\mathrm{H}$, benzylidine-H). 10.56 (s, $1 \mathrm{H}, \mathrm{NH}$ ). Anal. Calc. for $\mathrm{C}_{19} \mathrm{H}_{16} \mathrm{~N}_{2} \mathrm{O}_{3}$ : C, 71.25; H, 5.00; N, 8.75. Found: C, 71.05; H, 4.82; N, 8.55.

\section{N-(4-(1-(2-Carbamothioylhydrazono)ethyl)phenyl)-2-cyano-3-(4-methoxyphenyl) acrylamide (14)}


SOME REACTIONS OF N-(4-ACETYLPHENYL)-2-CYANOACET . . 227

Yield (65\%); Yellow crystals; Mp 250-252C ; IR (KBr): $\bar{\nu}=3432,3312$ $(\mathrm{NH} / \mathrm{SH}), 2214(\mathrm{C} \equiv \mathrm{N}) .1674(\mathrm{C}=\mathrm{O}) \mathrm{cm}^{-1}$; ${ }^{1} \mathrm{HNMR}$ (200 MHz, DMSO-d $\left.)_{6}\right): \delta=2.29$ (s, 3H, $\mathrm{CH}_{3}$ ), 3.87 (s, 3H, $\mathrm{OCH}_{3}$ ), 7.31-8.04 (m, 8H, Ar-H), 8.22 (s, 3H, benzylidine$\mathrm{H}), 10.16,10.37$ (2s, $4 \mathrm{H}, 3 \mathrm{NH} \& \mathrm{SH}$; exchange). Anal. Calc. for $\mathrm{C}_{20} \mathrm{H}_{19} \mathrm{~N}_{5} \mathrm{O}_{2} \mathrm{~S}: \mathrm{C}$, 61.06; H, 4.83; N, 17.81. Found: C, 60.94; H, 4.68; N, 17.50.

\section{2-(1-(4-(6-Amino-4-(4-chlorophenyl)-3,5-dicyano-2-oxo-pyridin-1(2H)yl)phen- yl)ethylidene)hydrazinecarbothioamide (15)}

A mixture of 6 ( 0.01 mole) and $\alpha$-cyano-4-chlorocinnamonitrile $10 \mathbf{b}$ (0.01 mole) in ethanol $(30 \mathrm{~mL})$ was treated with piperidine $(0.5 \mathrm{ml})$ and the reaction mixture was refluxed for 3h. The solid product which produced on heating was filtered and recrystallized from dioxane to give $\mathbf{1 5}$.

Yield (56\%); Yellow crystals; Mp 300-302C $\mathrm{C}^{\circ}$ IR (KBr): $\bar{\nu}=3318,3278$ $\left(\mathrm{NH} / \mathrm{NH}_{2}\right), 2218(\mathrm{C} \equiv \mathrm{N}) .1666(\mathrm{C}=\mathrm{O}) \mathrm{cm}^{-1} ;{ }^{1} \mathrm{HNMR}\left(200 \mathrm{MHz}, \mathrm{DMSO}-\mathrm{d}_{6}\right): \delta=$ 2.36 (s, 3H, $\mathrm{CH}_{3}$ ), 7.37-8.30 (m, 8H, Ar-H), 8.40 (br, 2H, $\mathrm{NH}_{2}$; exchange), 10.17, 10.29, 10.45 (3s, 3H, 2NH \& SH; exchange). Anal. Calc. for $\mathrm{C}_{22} \mathrm{H}_{16} \mathrm{~N}_{7} \mathrm{OSCl}$ : C, 57.20; H, 3.46; N, 21.23. Found: C, 57.03; H, 3.22; N, 21.00.

MS (EI): m/z (\%) = 387 [M+76( $\left.\left.\mathrm{NH}_{2} \mathrm{CSNH}_{2}\right)\right], 167$ (3.5), 146 (4.0), 118(13.4), 90 (21.3) and 59(100, base peak).

Preparation of compounds 16a, $b$ and 17a, $b$ : General procedure: A mixture of compound 6 (0.01 mole), appropriate $\alpha$-halo compound namely (chloroacetone 3a and p-nitrophenacyl bromide $3 \mathbf{e}$, ethyl chloroacetate $3 \mathbf{b}$ and ethy1- $\alpha$ bromopropionate $3 c)$ ( 0.01 mole) and sodium acetate ( 0.01 mole) in ethanol (30 mL) was refluxed for $3 \mathrm{~h}$. The solid product which produced on heating was collected and recrystallized from the proper solvents.

\section{2-Cyano-N-(4-(1-(2-(4-methylthiazol-2-yl) hydrazono) methyl) phenyl) acetamide} (16a)

Yield (65\%); Yellow crystals (Acetic acid); $\mathrm{Mp} 210-212^{\circ} \mathrm{C}$; IR (KBr): $\overline{\boldsymbol{V}}=$ $3108(\mathrm{NH}), 2198(\mathrm{C} \equiv \mathrm{N}), 1694(\mathrm{C}=\mathrm{O}) \mathrm{cm}^{-1} ;{ }^{1} \mathrm{HNMR}\left(200 \mathrm{MHz}, \mathrm{DMSO}-\mathrm{d}_{6}\right): \delta=$ 2.24, 2.37 (2s, 6H, 2CH $)$, 4.01 (s, 2H, $\mathrm{CH}_{2}$ ), 6.56, 11.01 (2s, 2H, 2NH; exchange), 7.65-7.87 (2d, 5H, Ar-H \& thiazole-H5). MS (EI): m/z (\%) = $313\left(\mathrm{M}^{+} 64.4\right), 298$ (16.4), 159 (11.0), 119 (39.7) and 65 (100, base peak). Anal. Calc. for $\mathrm{C}_{15} \mathrm{H}_{15} \mathrm{~N}_{5} \mathrm{OS}$ : C, 57.50; H, 4.79; N, 22.36. Found: C, 57.32; H, 4.52; N, 22.15.

2-Cyano-N-(4-(1-(2-(4-(4-nitrophenyl)thiazol-2-yl)hydrazono)ethyl)phenyl)acetamide (16b) 
Yield (60\%); Brown crystals (dioxane); Mp 270-270 C ; IR (KBr): $\bar{\nu}=3316$ (NH), 3088 (arom. CH), $2260(\mathrm{C} \equiv \mathrm{N}), 1678(\mathrm{C}=\mathrm{O}) \mathrm{cm}^{-1}$; ${ }^{1} \mathrm{HNMR}(200 \mathrm{MHz}$, DMSO-d $\mathrm{d}_{6}$ ): $\delta=2.30$ (s, 3H, $\mathrm{CH}_{3}$ ), 3.93 (s, 2H, $\mathrm{CH}_{2}$ ), 7.59- 8.29 (m, 10H, Ar-H \& thiazole-H5). 10.45 (s, 1H, NH; exchange). MS (EI): m/z (\%) = 420 (M 30.3), 354 (18.4), 249 (72.1), 132 (15.4) and 65(100, base peak). Anal. Calc. for $\mathrm{C}_{20} \mathrm{H}_{16} \mathrm{~N}_{6} \mathrm{O}_{3} \mathrm{~S}$ : C, 57.14; H, 3.80; N, 20.00. Found: C, 56.95; H, 3.59; N, 19.85.

\section{2-Cyano-N-(4-(1-(2-(4-oxo-4,5-dihydrothiazol-2-yl)hydrazono)ethyl)phenyl) acetamide (17a)}

Yield (70\%); Beige crystals (Benzene); Mp 245-247C ${ }^{\circ}$ IR (KBr): $\bar{\nu}=3276$ (NH), 2992 (aliph. $\mathrm{CH}), 2260(\mathrm{C} \equiv \mathrm{N}), 1712(\mathrm{C}=\mathrm{O}$; thiazolidinone), $1682(\mathrm{C}=\mathrm{O}$; amide) $\mathrm{cm}^{-1}$; ${ }^{1} \mathrm{HNMR}\left(200 \mathrm{MHz}\right.$, DMSO-d $\left.{ }_{6}\right): \delta=2.30\left(\mathrm{~s}, 3 \mathrm{H}, \mathrm{CH}_{3}\right), 3.85,3.92(2 \mathrm{~s}$, 4H, 2 $\mathrm{CH}_{2}$ ), 7.59, 7.96 (2d, 4H, Ar-H), 10.46, 11.89 (2s, 2H, 2NH; exchange). Anal. Calc. for $\mathrm{C}_{14} \mathrm{H}_{13} \mathrm{~N}_{5} \mathrm{O}_{2} \mathrm{~S}$ : C, 53.33; H, 4.12; N, 22.22. Found: C, 53.13; H, 3.98; N, 22.00 .

\section{2-Cyano-N-(4-(1-(2-(5-methyl-4-oxo-4,5-dihydrothiazol-2-yl)hydrazo-}

\section{no)ethyl)phenyl)acetamide (17b)}

Yield (63\%); White crystals (Acetic acid); Mp 250-252 Co; IR (KBr): $\bar{\nu}=3260$ (NH), 2948 (aliph. $\mathrm{CH}), 2262(\mathrm{C} \equiv \mathrm{N}), 1726$ (C=O; thiazoli-dinone), $1676(\mathrm{C}=\mathrm{O}$; amide) $\mathrm{cm}^{-1}$; ${ }^{1} \mathrm{HNMR}\left(200 \mathrm{MHz}, \mathrm{DMSO}-\mathrm{d}_{6}\right): \delta=1.48\left(\mathrm{~d}, 3 \mathrm{H}, \mathrm{CH}_{3}\right), 2.38(\mathrm{~s}, 3 \mathrm{H}$, $\mathrm{CH}_{3}$ ), 3.92 (s, 2H, $\mathrm{CH}_{2}$ ), 4.17 (q, 1H, thiazolidinone-H5), 7.59, 7.81 (2d, 4H, Ar-H), 10.44, 11.87 (2s, 2H, 2NH; exchange). Anal. Calc. for $\mathrm{C}_{15} \mathrm{H}_{15} \mathrm{~N}_{5} \mathrm{O}_{2} \mathrm{~S}$ : C, 54.71; $\mathrm{H}$, 4.55; N, 21.27. Found: C, 54.56; H, 4.38; N, 21.10.

Preparation of compounds 18 and 19: General procedure: A mixture of compound 16a and/or 17a (0.01 mole), salicylaldehyde (0.01 mole) and piperidine $(0.5 \mathrm{~mL})$ in dimethylformamide $(30 \mathrm{~mL})$ was refluxed for $3 \mathrm{~h}$. The resulting products which produced were collected and recrystallized from the proper solvents.

2-Imino-N-(4-(1-(2-(4-methylthiazol-2-yl)hydrazono)ethyl)phenyl)2H-chromene-

\section{3-carboxamide (18)}

Yield (73\%); Yellow crystals (Acetic acid); Mp 300-302C $\mathrm{C}^{\circ}$ IR (KBr): $\bar{\nu}=$ 3186 (NH), 2980 (aliph. CH), $1680(\mathrm{C}=\mathrm{O}) \mathrm{cm}^{-1}$; ${ }^{1} \mathrm{HNMR}$ (200 MHz, DMSO-d $\left.{ }_{6}\right): \delta=$ 2.16, 2.27 (2s, 6H, 2CH ), 6.31 (s, 1H, thiazole-H5), 7.25- 7.81 (m, 8H, Ar-H), 8.57 (s, 1H, chromene-H4), 9.25, 12.89 (2s, 2H 2NH; exchange), 11.40 (br, $1 \mathrm{H}, \mathrm{NH}$; 
exchange). Anal. Calc. for $\mathrm{C}_{22} \mathrm{H}_{19} \mathrm{~N}_{5} \mathrm{O}_{2} \mathrm{~S}$ : C, 63.30; H, 4.55; N, 16.78. Found: C, 63.12; H, 4.38; N, 16.44 .

2-Imino-N-(4-(1-(2-(4-oxo-4,5-dihydrothiazol-2-yl)hydrazono)ethyl)-phenyl)-2Hchromene-3-carboxamide(19)

Yield (67\%); Brown crystals (Dioxane); Mp 270-272Cㅇ IR (KBr): $\bar{\nu}=3170$ (NH), 2988 (aliph. CH), 1685 (C=O) cm ${ }^{-1}$; ${ }^{1} \mathrm{HNMR}$ (200 MHz, DMSO-d 6 ): $\delta=2.27$ (s, H, CH3), 4.10 (s, 2H, $\mathrm{CH}_{2}$ ), 7.20- 7.90 (m, 8H, Ar-H), 8.60 (s, 1H, chromeneH4), 9.30, 11.40, 12.40 (3s, 3NH; exchange). Anal. Calc. for $\mathrm{C}_{21} \mathrm{H}_{17} \mathrm{~N}_{5} \mathrm{O}_{3} \mathrm{~S}$ : C, 60.14; H, 4.05; N, 16.70. Found: C, 59.87; H, 3.80; N, 16.52.

MS (EI): m/z (\%) = 419 (M+41.2), 418(13.0), 306 (5.4), 173 (100, base peak), 172 (74.4), 145 (51.5) and 116 (26.6).

\section{2-(1-(4-(2-Imino-2H-chromene-3-carboxamido)phenyl)ethylidene)hyd-} razinecarbimidothioic acid (20)

A mixture of compound 6 (0.01 mole), salicylaldehyde (0.01 mole) and ammonium acetate $(0.01$ mole) in ethanol $(30 \mathrm{~mL})$ was refluxed for $1 \mathrm{~h}$. The solid product which produced on heating was collected and recrystallized from dioxane to furnish 20

Yield (70\%); Yellow crystals (Acetic acid); Mp 260-262C $\mathrm{C}^{\circ}$ IR (KBr): $\bar{\nu}=$ $3216(\mathrm{NH}), 2968$ (aliph-CH), $1682(\mathrm{C}=\mathrm{O}) \mathrm{cm}^{-1}$; ${ }^{1} \mathrm{HNMR}$ (200 MHz, DMSO-d ${ }_{6}$ ): $\delta=$ 2.27 (s, 3H, $\mathrm{CH}_{3}$ ), 7.25-7.98 (m, 8H, Ar-H), 8.23 (s, 1H, chromene-H4), 8.57, 9.24, 10.15, 12.91 (4s, 4H, 3NH \& SH; exchange). Anal. Calc. for $\mathrm{C}_{19} \mathrm{H}_{17} \mathrm{~N}_{5} \mathrm{O}_{2} \mathrm{~S}$ : C, 60.15; H, 4.48; N, 18.46. Found: C, 59.92; H, 4.30; N, 18.27.

MS (EI): m/z (\%) = 379 (M+5.5), 363 (9.4), 265 (12.3), 223 (19.0), 172 (71.0) and 118 (100, base peak).

\section{Preparation of compounds 21a,b: General procedure:}

A mixture of compound 1 (0.01 mole), appropriate phenolic aldehyde (salicylaldehyde or 2-hydroxynaphthaldehyde; 0.01 mole) and ammonium acetate (0.01 mole) in ethanol ( $30 \mathrm{~mL}$ ) was refluxed for $1 \mathrm{~h}$. The solid product which produced on heating was collected and recrystallized to furnish 21a and $22 \mathbf{b}$.

$\mathrm{N}$-(4-Acetylphenyl)-2-imino-2H-chromene-3-carboxamide (21a)

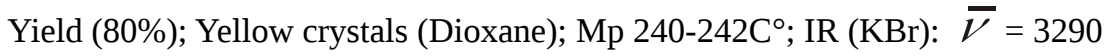
(NH), 2934 (aliph-CH), $1658(\mathrm{C}=\mathrm{O}) \mathrm{cm}^{-1}$; ${ }^{1} \mathrm{HNMR}$ (200 MHz, DMSO-d 6 ): $\delta=2.49$ 
(s, 3H, $\mathrm{COCH}_{3}$ ), 7.25- 8.00 (m, 8H, Ar-H), 8.58 (s, 1H, chromene-H4), 9.27, 13.12 (2s, 2NH; exchange). Anal. Calc. for $\mathrm{C}_{18} \mathrm{H}_{14} \mathrm{~N}_{2} \mathrm{O}_{3}$ : C, 70.58; H, 4.57; N, 9.15.

Found: C, 70.45; H, 4.32; N, 9.00.

\section{N-(4-Acetylphenyl)-3-imino-3H-benzo[f]chromene-2-carboxamide (21b)}

yield (70\%); Beige crystals (Methanol); Mp 250-252C; IR (KBr): $\bar{\nu}=3288$ (NH), 2918 (aliph-CH), 1656 (C=O) cm ${ }^{-1} ;{ }^{1} \mathrm{HNMR}$ (200 MHz, DMSO-d 6 ): $\delta=2.49$ (s, 3H, $\mathrm{COCH}_{3}$ ), 7.43- 8.48 (m, 10H, Ar-H), 9.17 (s, 1H, chromene-H4), 9.26, 13.15 (2s, 2NH; exchange). Anal. Calc. for $\mathrm{C}_{22} \mathrm{H}_{16} \mathrm{~N}_{2} \mathrm{O}_{3}$ : C, 74.15; H, 4.49; N, 7.85. Found: C, 73.95; H, 4.29; N, 7.60.

MS (EI): m/z (\%) = $356\left(\mathrm{M}^{+}\right.$20.5), 222 (33.5), 195 (18.1), 139 (28.4) and 120 (100, base peak).

Preparation of compounds 22a,b: General procedure: A mixture of compound 1 (0.01 mole), appropriate aldehyde (salicylaldehyde or 2-hydroxynaphthaldehyde; 0.01 mole) and sodium acetate (0.01 mole) was refluxed in acetic anhydride (30 mL) for $1 \mathrm{~h}$. The resulting solid was filtered off and recrystallized from dioxane.

\section{$N$-(4-Acetylphenyl)-2-oxo-2H-chromene-3-carboxamide (22a)}

yield (55\%); Beige crystals; Mp 260-262 C०; IR (KBr): $\bar{\nu}=3100(\mathrm{NH}), 1702$ (C=O; lactone), 1650 (C=O; amide) $\mathrm{cm}^{-1}$; ${ }^{1} \mathrm{HNMR}$ (200 MHz, DMSO-d $\left.{ }_{6}\right): \delta=2.49$ (s, 3H, $\mathrm{COCH}_{3}$ ), 7.45- 8.02 (m, 8H, Ar-H), 8.92 (s, 1H, chromene-H4), 10.87 (s, $\mathrm{NH}$; exchange). Anal. Calc. for $\mathrm{C}_{18} \mathrm{H}_{13} \mathrm{NO}_{4}$ : C, 70.35; H, 4.23; N, 4.56. Found: C, 70.15; H, 4.13; N, 4.40.

\section{$\mathrm{N}$-(4-Acetylphenyl)-2-oxo-2H-benzo[f]chromene-3-carboxamide (22b)}

yield (55\%); Brown crystals; Mp 270-272C; IR (KBr): $\bar{\nu}=3186(\mathrm{NH}), 1718$ (C=O; lactone). 1668 (C=O; amide) $\mathrm{cm}^{-1}$; ${ }^{1} \mathrm{HNMR}$ (200 MHz, DMSO-d $\left.\mathrm{d}_{6}\right): \delta=2.49$ (s, 3H, $\mathrm{COCH}_{3}$ ), 7.67- 8.69 (m, 10H, Ar-H), 9.56 (s, 1H, chromene-H4), 10.95 (s, $1 \mathrm{H}, \mathrm{NH}$; exchange). Anal. Calc. for $\mathrm{C}_{22} \mathrm{H}_{15} \mathrm{NO}_{4}$ : C, 73.94; H, 4.20; N, 3.92. Found: C, 73.75; H, 4.05; N, 3.70.

Preparation of compounds 24 and 26: General procedure: A mixture of 21a (0.01 mole), active methylene compounds (namely, malononitrile, ethyl cyanoacetate) (0.01 mole) and piperidine $(0.5 \mathrm{~mL})$ in dioxane $(30 \mathrm{~mL})$ was heated under reflux for 3h. The solid product which produced on heating was collected by filtration and recrystallized from acetic acid. 
SOME REACTIONS OF N-(4-ACETYLPHENYL)-2-CYANOACET ... 231 3-(4-Acetylphenyl)-2-amino-5-imino-4-oxo-4,5-dihydro-3H-chromeno-[3,4c]pyridine-1-carbonitrile (24)

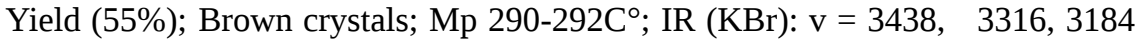
$\left(\mathrm{NH} / \mathrm{NH}_{2}\right), 2208(\mathrm{C} \equiv \mathrm{N}) 1650(\mathrm{C}=\mathrm{O}) \mathrm{cm}^{-1} ;{ }^{1} \mathrm{HNMR}\left(200 \mathrm{MHz}, \mathrm{DMSO}-\mathrm{d}_{6}\right): \delta=2.49$ (s, 3H, $\left.\mathrm{COCH}_{3}\right), 7.51-7.58(\mathrm{~m}, 8 \mathrm{H}, \mathrm{Ar}-\mathrm{H}), 7.79,8.40$ (2s, 3H, $\mathrm{NH}_{2} \& \mathrm{NH}$; exchange). Anal. Calc. for $\mathrm{C}_{21} \mathrm{H}_{14} \mathrm{~N}_{4} \mathrm{O}_{3}$ : C, 68.10; H, 3.78; N, 15.13. Found: C, 67.90; H, 3.64; N, 14.95.

\section{3-(4-Acetylphenyl)-2-hydroxy-5-imino-4-oxo-4,5-dihydro-3H-chromeno[3,4- c]pyridine-1-carbonitrile (26)}

Yield (60\%); Brown crystals; Mp 340-342C; IR (KBr): v = 3404 (NH/OH), $2208(\mathrm{C} \equiv \mathrm{N}) .1656(\mathrm{C}=\mathrm{O}) \mathrm{cm}^{-1} ;{ }^{1} \mathrm{HNMR}\left(200 \mathrm{MHz}, \mathrm{DMSO}-\mathrm{d}_{6}\right): \delta=2.49(\mathrm{~s}, 3 \mathrm{H}$, $\mathrm{COCH}_{3}$ ), 7.37-9.04 (m, 8H, Ar-H), 8.68 (br, 1H, OH; exchange), 11.66 (s, H, NH; exchange). Anal. Calc. for $\mathrm{C}_{21} \mathrm{H}_{13} \mathrm{~N}_{3} \mathrm{O}_{4}$ : C, 67.92; $\mathrm{H}, 3.50 ; \mathrm{N}, 11.32$. Found: C, 67.65; H, 3.25; N, 11.12.

\section{References:}

1. G. H. ElgEMEIE, A. H. ELGHANDOUR, A. M. ELZANATE, S.A. AHMED. J. Chem. Soc. Perkin Trans 1 21:3285(1997). Chem. Abstr. 128: 48171v (1998).

2. M. A. MASSOUD, M. MANSOUR. J. Pharm. Sci. 15: 94 (1999).

3. W. HUANG, J. LI, J. TANG, H. LIU, J. Shen, H. Jiang. Synth. Commun. 35:1351 (2005).

4. D. MIJIN, A. Marin Kovic. Synth. Commun 36: 193 (2006).

5. Y. KOBAYASHI AND T. HARAYAMA. Tetrahedron Letters 50: 6665 (2009).

6. S. BONDOCK, R. RABIE, H.A. ETMAN AND A.A. FADDA. Eur. J. 43:2122 (2008).

7. M.M. F. ISMAIL, Y. A. AMMAR, H.S.A. EL-ZAHABY, S.I. EISA1, S. BARAKAT Arch. Pharm. Life Sci., 340: 476 (2007).

8. K. KONSTANTINOS. (1984) Patent Schrift, 646 (1985) Chem. Abstr. 102, 184812v(1985).

9. Y. A. AMMAR, A. M. SH. EL-SHARIEF, A. A. MOHAMED, M. A. SALEM, A. G. AL-SEHEMI, M. S. A. EL-GABY.J. Chin. Chem. Soc. 51:975 (2004).

10. M. M. A. KHALIFA, H. K. H. SABET, M. H. HELAL, M. A. SALEM. ALAZHAR J. Pharm. Sci. 37: 168 (2008).

11. E. FARRAG, A. G. AL-SEHEMI, M. A. SALEM, H. KH. SABET, M. H. HELAL. Al-Azhar Bull. Sci. 19: 95 (2008).

12. Y. A. AMMAR, M. M. ALY, A. G. AL-SEHEMI, Y. A. MOHAMED, M. A. SALEM, M. S. A. EL-GABY. Phosphorus Sulfur, Silicon and the related elements 183 (7): 1710 (2008). 
13. Y. A. AMMAR, H. KH. THABET, M. M. ALY, Y. A. MOHAMED, M. M. ISMAIL, M. A. SALEM. Phosphorus Sulfur, Silicon and the related elements 185 (9):743 (2010).

14. S. G. KUCUKGUZEL, E. E. OUUCE, S. ROLLS, F. SAHIN, A. OZBEK. Eur. J. Med. Chem. 37:197 (2002).

15. G. CAPAN, N. ULUSOY, N. FRAGENC, M. KIRAZ. Monatshefte fur chemie 130:1399 (1999).

16. N. ERGENC, G. Capan. IL Farmaco 49:133 (1994).

17. J. J. BHATT, B. R. SHAH, H. P. SHAH, P. B. TRIVEDI, N. K. UNDAVIA, N.G. Desai. Indian j. Chem. 33B: 189 (1994).

18. L. BUKOWSKI, M. JANWIEC, Z. ZWOLSKA, Z. ANDREJCZYK. Pharmzie 53: 373 (1998).

19. C. J. ANDRES, J. J. BRONSON, S. V. ANDEA, M. S. DESHPANDE, P. J. FALK, K. A. GRANT, W. E. HARTE, H.T. HO, P. F. MISCO, J. G. Robertson, D. Stock, Y. A. Sun, W. Walsh, Bioorg. Med. Chem. Lett. 10: 715 (2000).

20. M. J. SCHNEIDER. Chem. Biol. Peraspect 10:155 (1996).

21. D. O. HAGAN. Nat. Prod. Rep. 17:435 (2000).

22. F. LAVELLE. Bull. Cancer 86:324 (1999).

23. G. R. WESISS, H. A. BURRIS, J. R. ECKARDAT, S. FIELDS, T. O. ROURKE, G. J. Rodriguez. Cancer Chemotherapy \& Biological Response Modifier 15:10 (1994).

24. A. Krauze, s. germane, o. eberlins, I. sturms, v. klusa, G. Duburs, Eut. J. Med. Chem.. 34. 301 (1999)

25. D. L. KLAYMAN, J. P. SCOVILL, J. F. BARTOSEVICH, C.J. MASON J. Med. Chem. 22:1367 (1979).

26. E. B. YANG, N. Y. ZHAO, K. ZHANG, P. MACK. Biochem. And Biophys Res. Commun. 260:682 (G. A. Rodrigues, M. Curr. Park Open Genetic Develop. 4: 15 (1994).

27. G. A. RODRIGUES, M. CURR. Park Open Genetic Develop. 4: 15 (1994).

28. S. A. AARONSON. Science 254:1146 (1991).

29. C. L. SAWAERS, C. T. Denny. Cell 77:171 (1994).

30. A. LEVITZKI, A. GAZIT. Science 267:1782 (1995).

31. T. R. BURKE. J. Drugs of the Future 17:119 (1992).

32. C. J. CHANG, R. L. GEAHLEN. J. Nat. Prod Lloydia 55:1529 (1992).

33. E. M. DORBRUSIN, D.W. Fry. Ann. Rep. Med. Chem. 27:169 (1992).

34. T. R. BURKE, B. LIM, V. E. MRAQUEZ, Z. H. LI, J. B. BOLEN, I. STEFANOVA, I. HORAK. J. Med. Chem. 36:425 (1993). 
SOME REACTIONS OF N-(4-ACETYLPHENYL)-2-CYANOACET .. 233

35. E.G. BROWN. Ring Nitrogen and Key Biomolecules: The Biochemistry of NHeterocycles, Kluwer Academic Pulb Group, 68 (1998).

36. K. UKAMA, T. ISHIGURO, Y. WADA, A. Nohara. Heterocycles 24: 1931 (1986).

37. D. HEBER. Arch. Pharm. 320:402 (1986).

38. G. H. ELGEMEIE, A. H. EL-GHANDOUR. Bull. Chem. Soc. Jpn. 63:1230 (1990). 